\title{
Does Congruence Between Incentive System and Locus of Control Affect Team Performance?
}

\author{
Siti Mutmainah ${ }^{1, *}$ and Slamet Sugiri ${ }^{2}$ \\ ${ }^{1}$ Diponegoro University, Semarang, Indonesia \\ ${ }^{2}$ Gadjah Mada University, Yogyakarta, Indonesia
}

\begin{abstract}
Teamwork is an essential element in most organizations; however, little is known about the best fit among incentive system, team composition, and team performance. This study examines whether the congruence between incentive system and locus of control (LoC) affects team performance. To reconcile opposite lines of arguments regarding the best incentive system for a team, this paper uses the social identity perspective and person-environment fit theory to understand behavior in a group process. One hundred and five postgraduate students were assigned to three-person work groups, where they completed an independent task under one of two types of incentive-individual and group incentiveafter their LoC was measured. Results suggest that group incentive results in an enhanced team performance and team performance is better when there is congruence between incentive system and LoC. Group incentive system combined with external LoC results in the best performance, while individual incentive results in a better team performance when combined with internal LoC.
\end{abstract}

\section{Introduction}

This research aims to examine whether the congruence between incentive system and locus of control (LoC) affects team performance. Group incentive system is the best motivator in an organizational setting that relies on teamwork [18, 23, 32, 39] because it encourages the whole team to work together and share information [13, 18]. This can be explained by organizational behavior literatures, for example social categorization theory [19] and goal interdependence theory [10]. Unlike the aforementioned literatures, the agency theory sees a potential for causing conflict among team members in the group-based reward [26]. The agency theory describes human conception (which is opportunistic, self-interested, and pursuing individualistic utility motivation [11]) as harnessing the lack of close relation between individual performance and group reward by bringing out social loafing [1,29].

Empirical evidence of the relation of incentive system and team performance shows inconsistent results. There are evidences that team performance is better when group incentive is applied $[18,23]$. However, other evidence shows that team performance is not

* Corresponding author: titikhasyim@yahoo.com 
significantly affected by the group incentive structure [26]. Meanwhile, that it is often the case that a team member refuses to collaborate and only give little effort for the team although he or she receives the same reward as others [9]. The inefficiency of group incentive is also revealed by other researchers [24].

In order to resolve the debate between theories and findings related to incentive systems and team performance, this research uses social identity perspective [12] and person-environment (P-E) fit theory [21] and investigate the role of personal traits at the group level [5, 22]. One of the important personality traits, which is stable, well documented, and indicating fundamental individual differences, is locus of control [3, 17]. This view on control affects an individual's accomplishments [1] and managerial effectiveness $[3,5]$.

Teamwork is an essential element in most organizations [23], so it is increasingly important to identify an effective strategy to build a team [20]. Since an organization consists of cooperating individuals, it is important to acquire the knowledge about interactions among team members and their effectiveness [15]. Meanwhile, empirical findings about the ways incentive affects the exchange of information and employees' performance are still limited and varied in number [35]. Ambrose and Kulik [2] who reviewed more than 200 empirical researches about work motivation conclude that little is known of the way teamwork is motivated. When organizations apply more team-based systems, research about team members' composition (e.g. LoC) and motivation (e.g. incentive) become more important as well.

We conduct an experiment involving 105 participants divided into 37 teams. The statistical testing results support our proposed hypothesis. Group incentive system encourages better team performance compared to individual incentive system. Empirically, it is also supported that the group incentive system could improve the performance of a team consisting of individuals with external LoC. Meanwhile, the team consisting of internal LoC individuals shows a better performance if the individual incentive system is applied.

Exploration for the matching of incentive schemes and locus of control in a team to produce an optimized teamwork is rarely examined in accounting management, especially using the experimental method. Experimental method researches with a team as analysis unit is also relatively scarce. Additionally, this research fills the gap between the disparity in the explanation of the appropriate team incentive systems.

\section{Hypothesis Development}

While agency theory and social cognitive theory support the application of the individual incentive system to improve team performance [26, 29], social categorization theory [19] and goals interdependence theory [10] strongly support group incentive system. To connect both poles, this research relates the incentive system with team performance based on the social identity perspective. This perspective is focused on conditions that determine selfdefinitions differently, which show the process of individual and group interaction in determining work motivation [12]. This perspective does not discern which one is more important or valid as source of motivation, but rather discern a more proper condition as source of motivation.

In the social identity framework theory, teamwork is a condition faced by team members to show 'the self' in a collective meaning. The group incentive scheme is a system that encourages employees to show their identities as part of a collective. Groupbased performance report will urge the employees to adopt a group frame [34]. The group frame encourages individuals to be more attentive of other individuals' outcomes and to build trust between them, while the individual frame encourages individuals to be self- 
centered. The individual-based incentive could lessen the information exchange between employees although economic incentive is given for the action [18].

Empirical evidence shows that group-based incentive is effective for organizations as it is mutually accountable, in which the members work for the same purpose as co-workers; in addition to the ease in measurement and evaluation $[1,23]$. In contrast, the individual incentive, which serves as individual performance compensation, can bring out 'selfish' behavior, such as the tendency to conceal information [38] and deter team activity such as information sharing and discussion [18]. Therefore, the group incentive system could motivate team members to coordinate and cooperate with each other to produce a much better team performance. Based on these arguments we propose the hypothesis:

$\mathbf{H}_{1}$ : Group incentive system encourages better team performance compared to individual incentive system

The influence of group incentive system on team performance is not entirely and consistently supported by numerous of previous empirical studies [for example 18, 23, 32 versus 24,26]. The meta-analysis shows the inconclusive results regarding the influence of incentive plans on performance [16]. Failure to reach a definitive conclusion from the aforementioned researches indicates that the main effect comparison is not adequate and that the possibility of mediation variable or moderator variable needs to be considered [37].

Person-environment (P-E) fit is generally defined as the match between individual and the working environment, which occur when both have similar characteristics [21]. For each individual there is an environment (interpersonal and non-interpersonal) which more or less matches his or her personality characteristics. The congruence or "best-fit" of an individual and the working environment can be seen from the good working performance, satisfaction, and the low level of stress in a system [4, 7].

Congruence between incentive system and LoC presumably affects the team performance. LoC personality dimension divides individuals based on the level of a person's acceptance of personal responsibility over what has happened to him or her [33]. Internal LoC individuals perceive a strong relation between their actions and the goals and the expected outcomes [33]. Therefore, the internal LoC characteristics will fit in an environment applying the individual incentive system rather than the group incentive. In the individual incentive system, there is a tight relation between individual performance and the received reward [29]. Additionally, this system also possesses a strong control of the individual over their performance [24]. When internal LoC individuals gathered in a team with the group incentive system, an effective team attribute of interdependence would be relatively difficult to obtain. Interdependence could be formed when team members are not entirely self-directed or not entirely independent [36]. The internal LoC team does not easily fulfill this attribute.

On the other hand, the group incentive system will match external LoC individuals. The group incentive scheme is designed to stimulate the collaboration between team members and the synergy within the team. Cooperation is assumed more attainable by external LoC individuals because they believe the chance and forces outside them affect success [33], in this case including the team, which becomes their closest working environment. Internal LoC individuals tend to be more independent and less appreciative of teamwork, while external LoC individuals tend to behave in contrast to internal LoC [30].

The congruence between incentive system and $\mathrm{LoC}$ is presumed to be positively responded by individuals. When congruence or P-E fit condition is attained, individuals will feel more comfortable and competent [8]. Additionally, P-E fit fulfills the fundamental needs of belonging and self-actualization, which in turn produces positive attitude and behavior [6]. These arguments give rise to the following hypotheses: 
$\mathbf{H}_{2}$ : Incentive system interacts with locus of control (LoC), such that internal LoC teams perform at higher levels at individual incentive than at group incentive, and external LoC teams perform at higher levels at group incentive than at individual incentive.

\section{Method}

To analyze our hypotheses, we conducted a laboratory experiment with a $2 \times 2$ design at a large university (Diponegoro University) in Indonesia. The participants were 105 accounting postgraduate students divided into 37 teams. All participants are students of the first semester $(75.2 \%)$ who have interacted with each other for at least 4 months and of the third semester $(24.8 \%)$ who have interacted for at least 1.5 years, so it is very likely for participants to cooperate as a team. Participants consist of $50.5 \%$ women and $49.5 \%$ men, with the average age of 30.97 and $82.9 \%$ of participants have worked.

Team performance (dependent variable) is measured by the number of tasks precisely completed by all of the member of the team. The incentive system (independent variable) is categorized into two, the individual incentive system and group incentive system. The individual incentive uses the equity norm basis, while group incentive uses equality norm.

The experiment is conducted in the following steps: (1) measuring participants' LoC (moderator variable) by Rotter's (1966) instrument [33]. (2) The participants are gathered in the same hour in different classes with different experiment conditions to prevent the internal validity threat of history, diffusion, and regression. The participants are divided to incentive system groups randomly, to overcome the selection threat, with three members in every group. To prevent reactivity and experimenter effects, the instruction is written in word-by-word details, and is to be read by the research assistant. To confirm that the participants understand their roles and tasks in the experiment, they are asked to answer four questions. (3) Participants work on the experimental task Raven's (2014) Standard Progressive Matrices (SPM) [31] as instructed in 10 minutes. This short duration of time is an effort to prevent the internal validity threat of maturation. The task chosen has a moderate difficulty level to prevent the internal validity threat of mortality. Each member in a group had to complete the different task. (4) Questionnaire sheets after experiment as manipulation check by giving Likert scale questions of five points (5) Incentive distribution. The hypotheses are tested by analysis of variance (ANOVA).

\section{Results}

The Cronbach's alpha scale of the manipulation check is 0.75 , meaning that this scale is reliable [28]. Additionally, the result of the Pearson correlation test shows that the questionnaire is a valid instrument for manipulation check. The mean of individual incentive condition $(\mathrm{n}=18)$ is 3.38 (SD 0.86$)$ and the mean of group incentive condition $(n=19)$ is 4.19 (SD 0.63) which signifies that manipulation design have effects as expected.

According to Table 1, the primary effect of group incentive system on performance $($ mean $=8.8772)$ is bigger than the individual incentive system $($ mean $=8.1852)$. According to Table 1 , the internal LoC team in the individual incentive system $($ mean $=8.5926)$ is not too different from internal LoC team within the group incentive system (mean $=8.5455)$. Meanwhile the external LoC team performs much better in the group incentive system $($ mean $=9.3333)$ compared to the individual incentive system $($ mean $=7.7778)$.

Results in Table 2 support our first hypothesis that the group incentive system encourages better team performance compared to the individual incentive system ( $\mathrm{F}=$ 4.242, $\mathrm{p}<0.05$ ). Results also indicate support for the second hypothesis that incentive system interacts with locus of control (LoC) such that internal LoC teams perform at higher 
levels at individual incentive than at group incentive, and external LoC teams perform at higher levels at group incentive than at individual incentive $(\mathrm{F}=4.789, \mathrm{p}<0.05){ }^{\dagger}$

Table 1. Descriptive Statistics

\begin{tabular}{lccc}
\hline \multirow{2}{*}{$\begin{array}{c}\text { Locus of Control } \\
\text { (LoC) }\end{array}$} & \multicolumn{3}{c}{ Mean and Standard Deviation of Team Performance } \\
\cline { 2 - 4 } & Individual Incentive System & Group Incentive System & Overall \\
\hline Internal LoC & 8.5926 & 8.5455 & 8.5667 \\
(Standard Deviation) & $(1.07726)$ & $(0.83030)$ & $(0.92306)$ \\
& $\mathrm{n}=9$ & $\mathrm{n}=11$ & $\mathrm{n}=20$ \\
External LoC & 7.7778 & 9.3333 & 8.5098 \\
(Standard Deviation) & $(1.61589)$ & $(0.69007)$ & $(1.46779)$ \\
& $\mathrm{n}=9$ & $\mathrm{n}=8$ & $\mathrm{n}=17$ \\
Overall & 8.1852 & 8.8772 & 8.5405 \\
(Standard Deviation) & $(1.39665)$ & $(0.85318)$ & $(1.18661)$ \\
& $\mathrm{n}=18$ & $\mathrm{n}=19$ & $\mathrm{n}=37$ \\
\hline
\end{tabular}

Table 2. ANOVA Result (Dependent Variable: Team Performance)

\begin{tabular}{lcccc}
\hline & Mean Square & df & F & Sig. \\
\hline Incentive System & 5.193 & 1 & 4.242 & 0.047 \\
Locus of Control (LoC) & 0.002 & 1 & 0.001 & 0.971 \\
Insentive*LoC & 5.863 & 1 & 4.789 & 0.036 \\
Error & 1.224 & 33 & & \\
R Squared =0,203 & & & & \\
(Adj. R Squared =0,131) & & & & \\
\hline
\end{tabular}

\section{Discussion}

This research aims to examine whether the congruence between incentive system and locus of control (LoC) affects team performance. The results support the proposed hypotheses. Findings related to the first hypothesis, that the group incentive system encourages a better team performance compared to the individual incentive system, is consistent with the previous research [for example 18, 23, 32].

The empirical findings supporting the second hypothesis is consistent with the P-E fit theory, in which the best performance is obtained by the best-fit. The small difference of internal LoC teams' performances in both incentive systems could be explained by the LoC characteristic, which perceive themselves as active agents. Internal LoC individuals perceive themselves as competent individuals in maintaining the control over their lives, and they generally have a great need for self-determination and competence [27].

Meanwhile, the improvement of performance in external LoC individuals is bigger than internal LoC in the incentive system shifting. When external LoC individuals cooperate, they could synergize and perform better than they do individually, because the inter-person interaction could decrease negative effects (especially fear and stress) [29]. Such a condition is consistent with the definition of teamwork as a cooperative process, which enables people to obtain extraordinary results [36].

These findings regarding external LoC individuals supplement the previous empirical findings that shows the superiority of internal LoC individuals [see 5, 14]. The findings of

To assure that team performance is not affected by accompanying factors such as subject demographic characteristics, an analysis of covariate (ANCOVA) test was also conducted. The result shows that team performance is not affected by either GPA $(\mathrm{F}=1.618$, $\mathrm{p}$ value $=0.213>0.05)$ nor the age of participants $(\mathrm{F}=0.767$, $\mathrm{p}$ value $=0.388>0.05)$. 
this research also contribute in resolving the debate between theories related to incentive system. From the managerial point of view, this research affirms the importance of team composition design [36] and its compatibility with the incentive system. This research supports the supplementary fit in order to obtain organizational goals [25].

This research has its limitations regarding external validation. This research also did not take into consideration the characteristics of the tasks. When a task requires a high level of information processing, the processes within the group, including open communication and performance strategy discussion, become more complex [15].

\section{References}

1. A. Ahlgren, I. Anderson, H. Skold, Essay in Management Control (School of Business Economics and Law, Goteborg University 2007)

2. M. L. Ambrose, C. T., Kulik, J. Mgt 25, 231 (1999)

3. C. Boone, W.V. Olffen, A.V. Witteloostuijn, AMJ 48, 889 (2005)

4. W.C. Borman, Curr. Dir. in Psyc. Sci. 13, 238 (2004)

5. P. Brownell, The Acc. Rev. 56, 844 (1981)

6. D.M. Cable, J.R. Edwards, J. App. Psych. 89, 822 (2004)

7. D.M. Cable, C.K. Parsons, Pers. Psych. 54, 1 (2001)

8. J.A. Chatman, AMR 14, 333 (1989)

9. R.M. Dawes, An. Rev. Psych. 31, 169 (1980)

10. M. Deutsch, The Int'l J. Conflict Mgt 1, 237 (1990)

11. K.M. Eisenhardt, AMR 14, 57 (1989)

12. N. Ellemers, D.D. Gilder, S.A. Haslam, AMR 29, 459 (2004)

13. G. Fisher, B. Sprinkle, L. L. Walker, J. Corp. Acc. \& Fin. 19, 35 (2008)

14. V. Frucot, W. T. Shearon, The Acc. Rev. 66, 80 (1991)

15. M.E. Gist, E.A. Locke, M.S. Taylor, J. Mgt 13, 237 (1987)

16. R. Guzzo, R. Jette, R. Katzell, Pers. Psych. 38, 275 (1985)

17. T.A. Judge, J.E. Bono, J. Appl. Psych. 86, 80 (2001)

18. K. Kelly, BRIA 22, 43 (2010).

19. H. Kim, K.L. Sutton, Y. Gong, Asia Pac. J. Mgt. 30, 31 (2013)

20. A. Kramer, D. P. Bhave, T. D. Johnson, Pers. \& Ind. Diff. 58, 132 (2014)

21. A.L. Kristof-Brown, R.D. Zimmerman, E.C. Johnson, Pers. Psych. 58, 281 (2005)

22. J.A. LePine, B.R. Buckman, E.R. Crawford, J.R. Methot, HR Mgt Rev. 21, 311 (2011)

23. T. Libby, L. Thorne, BRIA 21, 57 (2009)

24. H.M.McGee, A.M.Dickinson, B.E.Huitema, K.M.Cullig, Perf.Impr.Quar.19,101(2006)

25. P.M. Muchinsky, C.J. Monahan, J. Voc. Behav. 31, 268 (1987)

26. D. Naranjo-Gil, G. Cuevas-Rodriguez, A. Lopez-Cabrales, BRIA 24, 177 (2012)

27. T. W. H. Ng, K. L. Sorensen, L. T. Eby, J. Org. Behav. 27, 1057 (2006)

28. J.C. Nunnaly, Psychometric Theory (McGraw-Hill, New York, 1978)

29. C.C. Pinder. Work Motivation in Organizational Behavior (Prentice-Hall, NJ 1998)

30. C.M. Ramirez. Teams: A Competency Based Approach (Routledge, 2013)

31. J.C. Raven. Raven's Progressive Matrices (Pearson, 2014)

32. S. P. Ravenscroft, S. Haka, BRIA 8, 114 (1996)

33. J.B. Rotter,. Psych. Mono.: Gen.\& Appl. 80, 1 (1966)

34. C. Rowe, The Acc. Rev. 79, 1153 (2004)

35. E. Siemsen, S. Balasubramaniam, A.V. Roth, Mgt. Sci. 53, 1533 (2007)

36. P. Taricone, J. Luca. Successful Teamwork: A Case Study (HERDSA 2002)

37. D. Tjosvold, Human Relations 37, 743 (1984)

38. M. S. Van Alstyne, HBR 83, 24 (2005)

39. S. M. Young, J. Fisher, T. M. Lindquist, The Acc. Rev. 68, 466 (1993) 